\title{
RELAÇÃO DA VARIABILIDADE DA TEMPERATURA DO AR E OS CASOS DE DENGUE EM CURITIBA DE 2011 A 2015
}

\author{
Julyana Baroni da Silva ${ }^{(a)}$, Fernanda Crystina Souza ${ }^{(b)}$ \\ (a) Geografia, Universidade Federal do Paraná, julyanabaroni@ufpr.br \\ (b) Geografia, Universidade Federal do Paraná, fernandacrystina@ufpr.br
}

Eixo: Climatologia em Diferentes Níveis Escalares: Mudanças e Variabilidades

\begin{abstract}
Resumo
Mediante o cenário preocupante sobre a intensidade e frequência das epidemias de dengue no Brasil, fez-se necessário intensificar os estudos relacionados à doença para que haja um auxílio na criação de políticas públicas para conscientização da população e controle do mosquito Aedes aegypti. As dinâmicas climáticas e, principalmente, o aumento da temperatura, interferem diretamente na proliferação do vetor das patologias em questão, assim como alguns fatores sociais, que são responsáveis pelo número acentuado de registros em determinadas regiões. O modelo de estudo proposto utiliza de dados de temperatura em Curitiba para relacioná-los com ocorrência de dengue na cidade. A análise do aumento da temperatura expressou índices crescentes nos casos da enfermidade em questão e também correlações lineares com valores acima de 0,72 , demonstrando assim alta relação entre os casos de dengue e os valores médios de temperatura.
\end{abstract}

Palavras chave: Clima, Temperatura do Ar, Dengue

\section{Introdução}

O presente trabalho tem como objetivo apresentar resultados de uma pesquisa que relaciona a variabilidade da temperatura do ar na cidade de Curitiba com a ocorrência de casos de dengue, sendo essa doença transmitida pelo mosquito Aedes aegypti. O estudo desse cenário fez-se ainda mais necessário quando a conjuntura mundial de mudanças climáticas ganhou mais espaço e visibilidade. Como fator condicionante para a proliferação do vetor das doenças em questão, a temperatura média anual no Paraná varia entre $14^{\circ}$ e $22^{\circ} \mathrm{C}$, sendo as temperaturas ideais para fecundação dos ovos do mosquito de $18^{\circ}$ a $32^{\circ} \mathrm{C}$. Isso demonstra que no verão o mosquito encontra melhores condições para sua reprodução, o que facilita a circulação viral em determinada área.

A dengue é, majoritariamente, registrada no meio urbano. Este ambiente possui características climáticas particulares, já que o clima urbano advém da interação entre sociedade e natureza no meio urbano, onde o meio natural sofre modificações resultantes do processo de desenvolvimento que se vive atualmente, onde determinados ambientes são negligenciados pela gestão pública. Isto favorece o surgimento de problemas particulares e da criação de uma esfera favorável à procriação de vetores responsáveis por diversas 
doenças humanas.

De acordo com a Organização Mundial da Saúde (2016), estima-se que 50-100 milhões de pessoas sejam infectadas com o vírus dengue em todo o mundo. Apenas no Brasil, em 2015, foram mais de 1,5 milhão de casos notificados. Desses, 46.943 casos só no Estado do Paraná, um aumento de aproximadamente 100\% em relação a 2014, com 22.701 casos prováveis, segundo o site do Portal da Saúde (2016).

\section{Materiais e Métodos}

A pesquisa foi desenvolvida através do uso de duas variáveis, a temperatura média do ar em Curitiba, no Paraná e o total de casos de dengue registrados por mês no município com o objetivo de relaciona-las e demonstrar como a variabilidade da temperatura do ar interfere na proliferação do mosquito Aedes Aegypti e por consequência no número de casos de dengue na área de estudo, com isso a hipótese desse trabalho é que nos anos em que maiores temperaturas médias do ar foram registradas, o número de casos autóctones de dengue tenham aumentado na área de estudo. Curitiba foi selecionada para o estudo por iniciar os registros de casos autóctones de dengue tardiamente em comparação aos demais municípios do estado do Paraná. Os dados de temperatura foram coletados pela estação automática da cidade do Instituto Nacional de Meteorologia INMET) para o período de 2011 a 2016, através dos dados diários foram calculadas médias mensais para os sete anos da escala adotada, esse período foi selecionado pois é a partir de 2011 se dá pela disponibilidade dos dados junto a Secretaria Municipal de Saúde, esses dados foram somados todos os casos registrados para cada mês durante os anos de análise. Após a coleta dos dados, foram criados gráficos que representam no tempo as temperaturas médias para Curitiba com o objetivo de analisar os anos com maiores temperaturas médias registradas, que poderiam representar o aumento no número de casos registrados. Além disso foram calculados valores de regressão linear para os meses todos os meses no período de selecionado com o objetivo de analisar a correlação entre as variáveis.

\section{Discussões}

Os resultados obtidos através da análise das médias das temperaturas para Curitiba e da soma dos casos autóctones demonstraram uma variabilidade entre os $10^{\circ} \mathrm{C}$ e $25^{\circ} \mathrm{C}$ em média para a área de estudo e com isso também a relação entre essa variação, que aponta para as condições ideias da reprodução do vetor da doença, conforme figura 1 . 


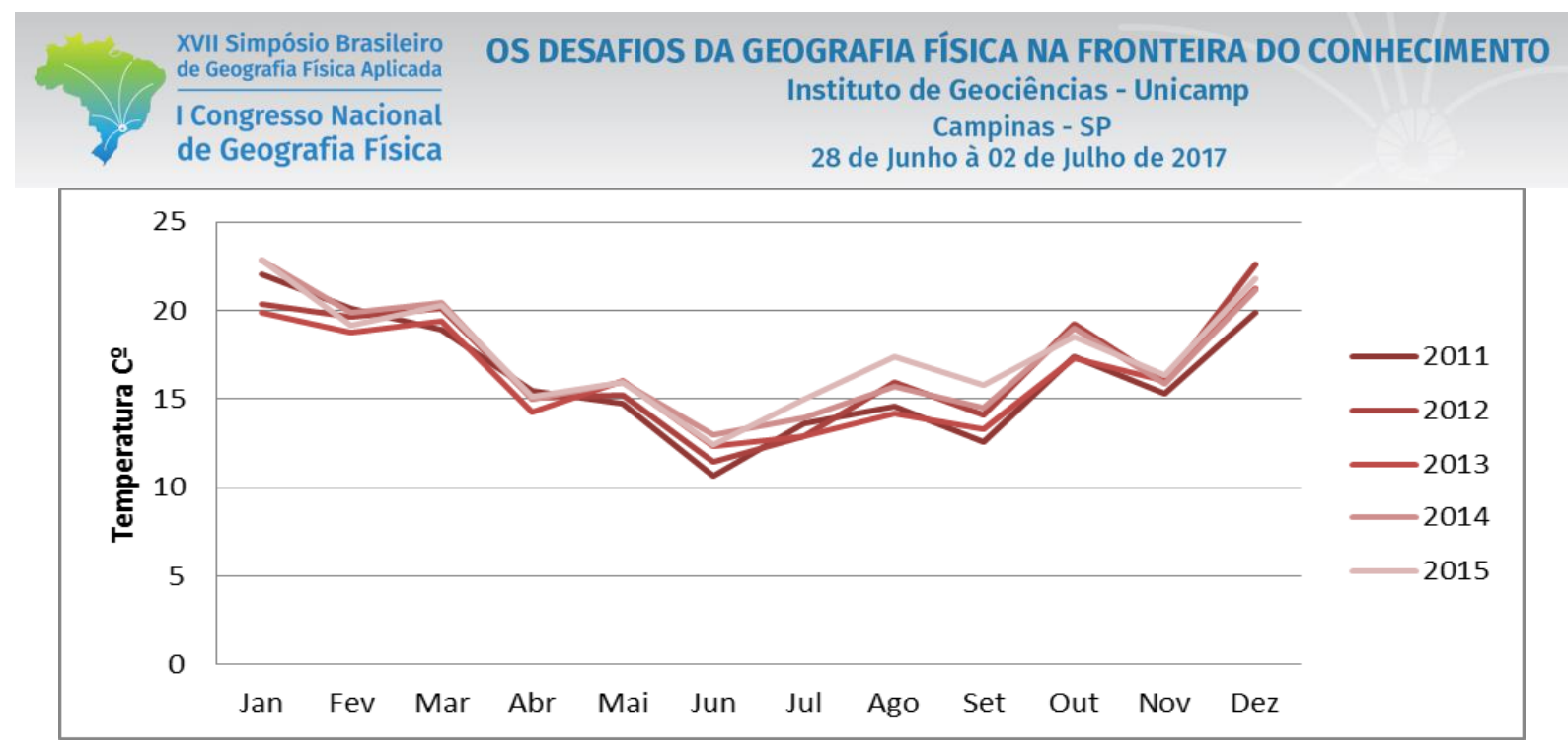

Figura 1 - Temperatura Média do Ar Curitiba - PR

Considerando a temperatura de $18^{\circ}$ a $32^{\circ} \mathrm{C}$ como ideal para a reprodução do mosquito da dengue, pode-se inferir que essa variabilidade da temperatura do ar demonstra como a cidade está vulnerável ao Aedes Aegypt em algumas estações do ano, como é o caso do verão (estação que apresenta chuvas bem distribuídas, o que auxilia na formação de criadouros). Considerando o ano de 2015, é possível perceber um verão com temperaturas que variaram de $18^{\circ} \mathrm{C}$ a $24^{\circ} \mathrm{C}$ com características bastante propícias para reprodução do vetor, facilitando a circulação viral da dengue na área de estudo, o mês de março apresentou picos de temperatura acima de $20^{\circ} \mathrm{C}$, que pode apontar um risco maior de casos de dengue em Curitiba no mês de abril, onde é possível perceber a repercussão dessa variação frente a doença. O ano de 2014 representa o início de um aumento nas temperaturas médias registradas na região, conforme pode ser visto na tabela I, que pode indicar e explicar o aumento no número de casos autóctones em Curitiba até o ano de 2016. Mesmo as temperaturas médias sendo registradas abaixo de $20^{\circ}$ é importante ressaltar que valores acima da média ocorreram e podem ter perpetuado, condicionando assim a proliferação do mosquito, caso esse que se repete para o ano de 2015. Essas relações, entre a variabilidade anual da temperatura do ar, as médias anuais e os casos de dengue pode ser constatada através da figura 2, que apresenta o número de casos autóctones por mês nos anos do período de estudo.

Tabela I. Temperaturas Médias Curitiba - PR

\begin{tabular}{cc}
\hline Ano & Temperatura Média \\
\hline $\mathbf{2 0 1 1}$ & 16,26 \\
$\mathbf{2 0 1 2}$ & 16,87 \\
$\mathbf{2 0 1 3}$ & 16,30 \\
$\mathbf{2 0 1 4}$ & 17,27 \\
$\mathbf{2 0 1 5}$ & 17,55 \\
\hline
\end{tabular}




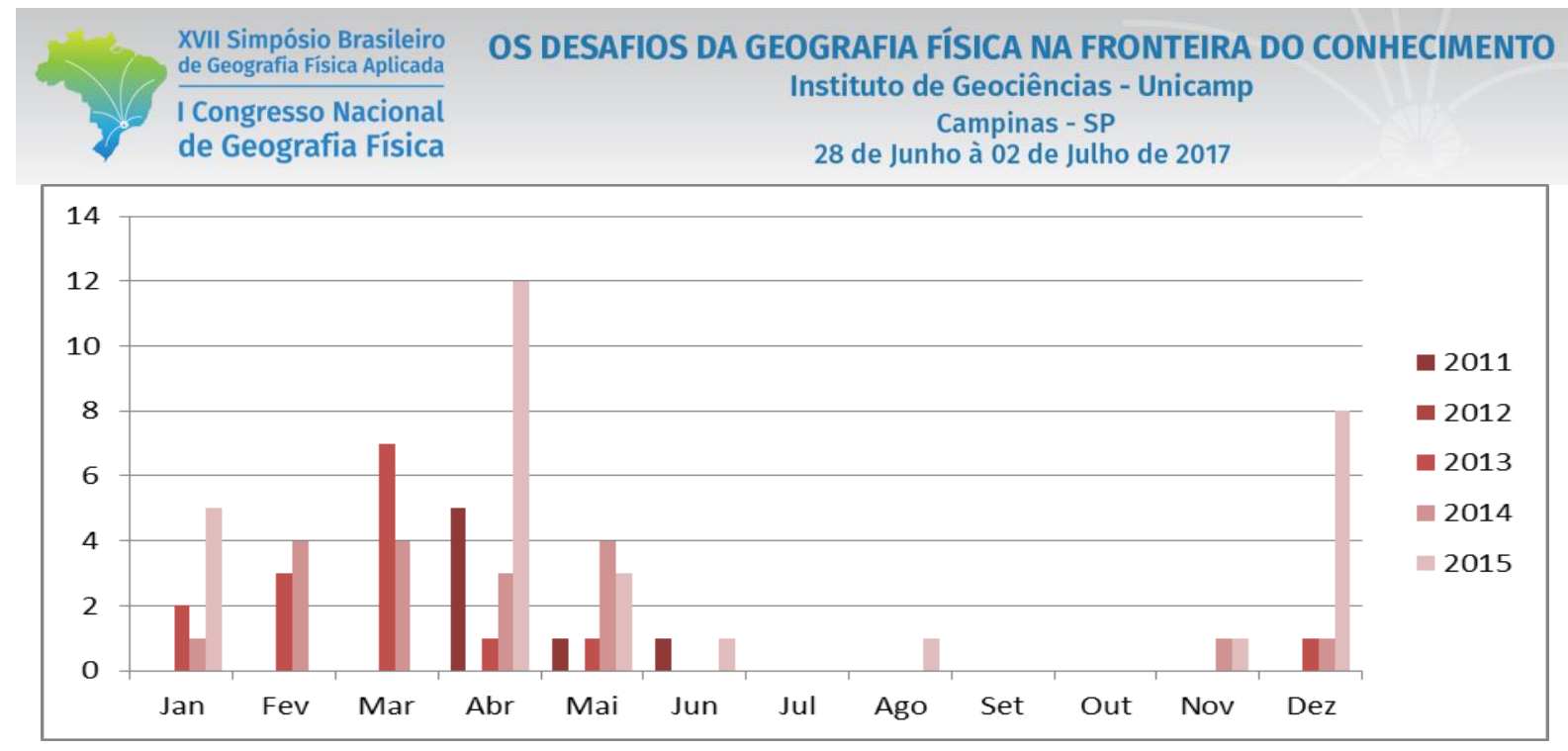

Figura 2. Número de casos Autóctones de Dengue - Curitiba - PR

A cidade de Curitiba apresentou criadouros do mosquito da dengue pela primeira vez depois de 10 anos no ano de 2012 (PREFEITURA MUNICIPAL DE CURITIBA, 2013). Devido às temperaturas mais elevadas no começo do verão de 2012/2013 é possível perceber que o ano de 2013 apresentou um número elevado de casos autóctones quando comparado aos anos anteriores. Uma hipótese para esse fato é que a fase de maturação do mosquito da dengue é de cerca de 10 dias em condições favoráveis, podendo os ovos resistirem até um período de 450 dias para então transformar-se em larvas (IOC/FIOCRUZ,2016).

Nos anos de 2014 e 2015, apesar de apresentarem temperaturas médias de $17,27{ }^{\circ} \mathrm{C}$ e $17,55{ }^{\circ} \mathrm{C}$, respectivamente, os casos notificados não foram tão altos. Pode-se inferir que tal resultado varia, também, de acordo com os índices de pluviosidade na cidade, já que além da temperatura entre $18^{\circ}$ e $32^{\circ} \mathrm{C}, \mathrm{o}$ mosquito necessita de criadouros com água parada para deposição dos ovos.

Tabela II. Valores de Regressão Linear $\left(\mathrm{R}^{2}\right)$ para os casos de Dengue e Temperatura Média.

\begin{tabular}{cc}
\hline Meses & $\mathbf{R}^{\mathbf{2}}$ \\
\hline Janeiro & 0,8321 \\
Fevereiro & 0,7583 \\
Março & 0,7652 \\
\hline Abril & 0,7242 \\
Maio & 0,8372 \\
Junho & 0,8017 \\
Julho & 0,7856 \\
Agosto & 0,8076 \\
Setembro & 0,8079 \\
Outubro & 0,7584 \\
Novembro & 0,7946 \\
Dezembro & 0,838 \\
\hline
\end{tabular}




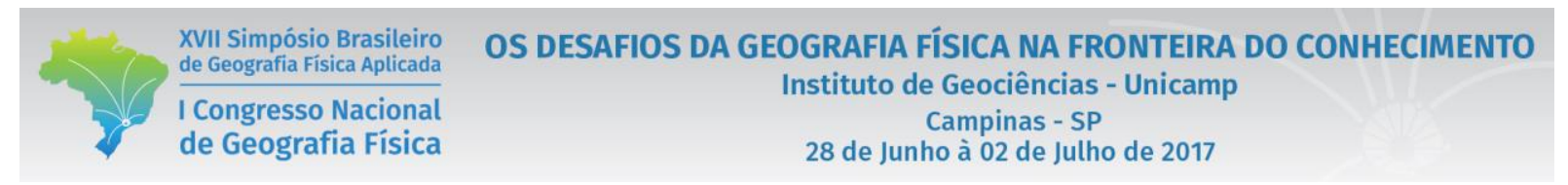

Os valores calculados para a regressão linear apontam uma alta relação entre as duas variáveis analisadas, as temperaturas médias e o total de casos de dengue mensais. Sendo os menores valores de relação para os meses de abril e outubro, outubro pode ser explicado por ter registrado temperaturas médias abaixo de $20^{\circ} \mathrm{C}$ nos últimos anos. Abril foi o mês com o maior número de casos registrados em todo o período, o que pode ter sido ocasionado por outros fatores condicionantes, como o total de chuvas e dados sociais, não abordados neste trabalho.

Essa breve análise a respeito dos casos de dengue de Curitiba confirma a hipótese apresentada no início da pesquisa, de que uma variabilidade na temperatura do ar da cidade tenha interferido de maneira condicionante ao aumento nos casos autóctones da doença. Além disso, também pode sugerir outras 3 análises, como a espacialização dos dados censitários, que podem apontar regiões com e sem acesso ao tratamento de água, esgoto e coleta de lixo, situações também condicionantes para a proliferação do mosquito, além dos índices de pluviosidade para a região, que interferem na dinâmica do vetor e também a análise das políticas públicas atuais frente a doença e por consequência as demais doenças transmitidas pelo mesmo mosquito. Ao considerar essas variáveis é possível construir uma previsão na variação dos dados para a doença e assim aplicar os conhecimentos da climatologia geográfica as políticas públicas em saúde.

\section{Bibliografia}

COSTA, F. S. Dinâmica populacional de Aedes aegypti (L) em área urbana de alta incidência de dengue. Rev. Soc. Bras. Med. Trop., v. 41, n. 3, p. 309-12, Uberlândia, MG, 2008.

FOGAÇA, T. K. Dengue: Circulação viral e epidemia de Paranavaí/PR.174 f. Dissertação de Mestrado, Programa de Pós-Graduação em Geografia, Setor de Ciências da Terra, Universidade Federal do Paraná. Curitiba, PR, 2015.

INSTITUTO OSWALDO CRUZ, FUNDAÇÃO OSWALDO CRUZ. Dengue, vírus e vetor. Disponível em

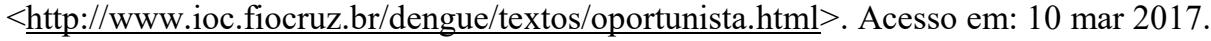

MENDONÇA, F. Geografia Socioambiental. In: MENDONÇA, F. \& KOZEL, S. Elementos de Epistemologia da Geografia Contemporânea. Curitiba: Editora da UFPR, 2002.CASTRO, M. H. G. Avaliação do sistema educacional brasileiro: tendências e perspectivas. Ensaio: avaliação e políticas públicas em educação, Rio de Janeiro, v. 6, n. 20, p. 303- 364, jul./set. 1998.

ORGANIZAÇÃO MUNDIAL DA SAÚDE. Dengue. 2016. Disponível em: <http://www.who.int/denguecontrol/faq/en/>. Acesso em: 17 jan. 2017.

PREFEITURA MUNICIPAL DE CURITIBA, Prestação de Contas- Monitoramento Quadrimestral - SUS CURITIBA. Jan-abr 2013. 83 p. 